\title{
Localization and phosphorylation of Plasmodium falciparum nicotinamide/ nicotinate mononucleotide adenylyltransferase (PfNMNAT) in intraerythrocytic stages
}

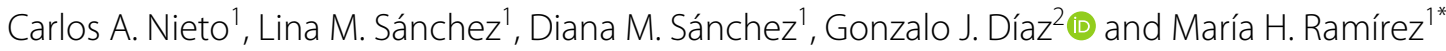

\begin{abstract}
Background: Nicotinamide adenine dinucleotide (NAD+) is an essential molecule in the energy metabolism of living beings, and it has various cellular functions. The main enzyme in the biosynthesis of this nucleotide is nicotinamide/nicotinate mononucleotide adenylyltransferase (NMNAT, EC 2.7.7.1/18) because it is the convergence point for all known biosynthetic pathways. NMNATs have divergences in both the number of isoforms detected and their distribution, depending on the organism.
\end{abstract}

Methods: In the laboratory of basic research in biochemistry (LIBBIQ: acronym in Spanish) the NMNATs of protozoan parasites (Leishmania braziliensis, Plasmodium falciparum, Trypanosoma cruzi, and Giardia duodenalis) have been studied, analysing their catalytic properties through the use of proteins. Recombinants and their cellular distribution essentially. In 2014, O'Hara et al. determined the cytoplasmic localization of NMNAT of $P$. falciparum, using a transgene coupled to GFP, however, the addition of labels to the study protein can modify several of its characteristics, including its sub-cellular localization.

Results: This study confirms the cytoplasmic localization of this protein in the parasite through recognition of the endogenous protein in the different stages of the asexual life cycle. Additionally, the study found that PfNMNAT could be a phosphorylation target at serine, tyrosine and threonine residues, and it shows variations during the asexual life cycle.

Conclusions: These experiments confirmed that the parasite is situated in the cytoplasm, fulfilling the required functions of NAD+ in this compartment, the PfNMNAT is regulated in post-transcription processes, and can be regulated by phosphorylation in its residues.

Keywords: Plasmodium falciparum, NAD+ metabolism, Malaria, PfNMNAT, Immunolocalization, Phosphorylation

\footnotetext{
${ }^{*}$ Correspondence: mhramirezh@unal.edu.co

${ }^{1}$ Laboratorio de Investigaciones Básicas en Bioquímica (LIBBIQ), Facultad

de Ciencias, Universidad Nacional de Colombia, Sede Bogotá, Bogotá

D.C., Colombia

Full list of author information is available at the end of the article
}

(c) The Author(s) 2018. This article is distributed under the terms of the Creative Commons Attribution 4.0 International License (http://creativecommons.org/licenses/by/4.0/), which permits unrestricted use, distribution, and reproduction in any medium, provided you give appropriate credit to the original author(s) and the source, provide a link to the Creative Commons license, and indicate if changes were made. The Creative Commons Public Domain Dedication waiver (http://creativecommons.org/ publicdomain/zero/1.0/) applies to the data made available in this article, unless otherwise stated. 


\section{Background}

Plasmodium falciparum causes malaria and is the leading parasitic cause of death worldwide [1]. Given that, to date, there is no clinically available vaccine and considering the recent increase in drug-resistant parasite strains, it is necessary to find proteins that serve as therapeutic targets for control of the disease [2].

During its asexual life cycle, the parasite infects erythrocytes, increasing oxidative stress intracellular after haemoglobin degradation. For this reason, the parasite has a variety of antioxidant systems that depend directly on the reducing power of the cellular content of $\mathrm{NADPH}$. In addition to infecting the erythrocyte, $P$. falciparum increases the activity of the pentose phosphate cycle, NAD + synthesis, and the expression of glycolytic enzymes in order to adapt to the intracellular environment $[3,4]$. Therefore, the role of $\mathrm{NAD}(\mathrm{P})+$ is essential since it is a key factor in some essential biological and biochemical processes of the parasite [5]. That is why the identification and characterization of the enzymes involved in its biosynthesis prove interesting. One of the most important enzymes in this pathway is the nicotinamide/nicotinate mononucleotide adenylyltransferase (NMNAT; EC:2.7.7.1) as it is the point of convergence of the two NAD+ biosynthetic pathways, de novo and salvage [6]. NMNAT has been identified in organisms as diverse as archaea, bacteria and eukaryotes $[7,8]$. In humans, three isoforms (NMNATs 1, 2 and 3) have been identified in the nucleus, Golgi apparatus and mitochondria, respectively $[9,10]$. Each of them has specific sequences that allow its intracellular localization.

Plasmodium falciparum NMNAT has already been identified [11, 12], and its tertiary structure has also been recently resolved by X-ray analysis [13]. This article describes the sub-cellular localization, phosphorylation and variations of NMNAT during the asexual life cycle of the parasite.

\section{Methods}

\section{Synthesis and evaluation of polyclonal anti-His-PfNMNAT} antibodies

IgG antibodies were obtained using the previously standardized protocol [14], in which $50 \mu \mathrm{g}$ of recombinant protein previously obtained in another job [11] was used to perform 4 inoculations in 6-week-old BALB-C mice. Blood collection was performed every 8 days after inoculations. Antibodies were purified using affinity chromatography [15]. To obtain IgY, 19-week old chickens (Babcock Brown) were inoculated 4 times with $150 \mu \mathrm{g}$ of the recombinant protein [16]. Eggs and blood were collected from day 0 to 1 month after the last inoculation. Antibodies were purified from egg yolk by thiophilic resin chromatography. For the evaluation of antibodies, different concentrations of recombinant His-PfNMNAT (3-125 ng) were separated by SDS-PAGE, electroblotted onto a PVDF membrane and developed with HRP. As a primary antibody, the sera used were obtained from avian (blood and egg yolk) and murine models at a dilution of 1:5000. As a control, $125 \mathrm{ng}$ of BSA was used.

\section{Plasmodium falciparum culture}

FCR-3 strains of $P$. falciparum were cultured in vitro [17]. The parasites were synchronized with $5 \%$ sorbitol at $37{ }^{\circ} \mathrm{C}$ for $10 \mathrm{~min}$ [18]. Synchronic cultures in the ring stage were maintained in culture until reaching the trophozoite and schizont stages. Parasites at different asexual stages were obtained by centrifugation at $4000 \times g$ for $5 \mathrm{~min}$, and erythrocytes were lysed with $0.01 \%$ saponin in PBS buffer at $4{ }^{\circ} \mathrm{C}$ for $15 \mathrm{~min}$. The parasites were recovered by centrifugation at $17,000 \times g$ for $15 \mathrm{~min}$, and then they were washed with $1 \times$ PBS until complete removal of the erythrocyte membrane and haemoglobin residues.

\section{Collection of the cytoplasmic protein extracts}

Approximately 2-4 million parasites were resuspended in $100 \mu \mathrm{l}$ of Tris-magnesium gelatin (TMG) buffer $(10 \mathrm{mM}$ Tris- $\mathrm{HCl}, \mathrm{pH}=7.5,1.5 \mathrm{mM} \mathrm{MgCl}, 10 \mathrm{mM}$ B-mercaptoethanol, and $10 \%$ glycerol) and protease inhibitor (Sigma, P8340; $1 \mathrm{mM}$ AEBSF, $14 \mu \mathrm{M}$ E64, $15 \mu \mathrm{M}$ pepstatin A, $40 \mu \mathrm{M}$ bestatin, $20 \mu \mathrm{M}$ leupeptin, and $0.8 \mu \mathrm{M}$ aprotinin). The extracts were then lysed by incubation with $0.2 \% \mathrm{NP}-40$ at $4{ }^{\circ} \mathrm{C}$ for $30 \mathrm{~min}$ and sonicated for $30 \mathrm{~s}$ with $50 \%$ amplitude. Cell debris was removed by centrifugation at $17,000 \times g$ for $30 \mathrm{~min}$ at $4{ }^{\circ} \mathrm{C}$.

\section{Immunodetection of PfNMNAT}

Approximately $80-100 \mu \mathrm{g}$ of soluble protein extract was separated on $12 \%$ SDS-PAGE gels and transferred to PVDF membranes (Thermo) for $2 \mathrm{~h}$ at $200 \mathrm{~mA}$ in electrotransfer buffer (Tris base $25 \mathrm{mM}, 192 \mathrm{mM}$ glycine and $10 \% \mathrm{~V} / \mathrm{V}$ methanol, $\mathrm{pH}$ 8.3). The membranes were blocked in TBST-milk (TBST-L) for $12 \mathrm{~h}$ and incubated for another $12 \mathrm{~h}$ with the previously obtained sera (IgY or IgG) at a dilution of 1:1000 in TBST-L. Three washes were performed with TBST-L for $10 \mathrm{~min}$ each, before the samples were incubated for $2 \mathrm{~h}$ with the secondary antibody anti-mouse IgG or anti-chicken IgY coupled to biotin $(1: 8000)$ and 3 washes were made with TBST-L. The immunodetection reaction was developed with the chromogenic BCIP/NBT substrate system for streptavidin-conjugated alkaline phosphatase. The recombinant protein MBP-PfNMNAT was used as a positive control [19]. 


\section{Immunofluorescence of PfNMNAT}

To determine the subcellular localization of the endogenous protein by immunofluorescence, the protocol reported by Tokin et al. [20] was followed, and the preimmune serum of the immunized chickens was used as the negative control. The plates were mounted with $10 \mu \mathrm{l}$ of Fluoromount (Sigma) per slide, and the images were recorded with the Nikon $\mathrm{C} 1$ plus confocal fluorescence microscope using a $100 \times$ objective.

\section{Identification of protein levels}

To obtain parasites in a single stage, the culture was subjected to 3 synchronization cycles with sorbitol $5 \%$, with pauses of $96 \mathrm{~h}$ (2 life cycles), between each synchronization. The parasites were obtained and lysed as mentioned above, we continued with the same immunodetection protocol where approximately $150 \mu \mathrm{g}$ of protein was loaded for each of the stages. The antibodies used were those obtained from chicken blood. The recombinant protein MBP-PfNMNAT was used as a positive control [19].

\section{Immunoprecipitation of PfNMNAT}

Cytoplasmic protein extracts were prepared as described above using $1 \mathrm{mM} \mathrm{Na} V_{3} \mathrm{VO}_{4}$. The extract was clarified for $1 \mathrm{~h}$ at $4{ }^{\circ} \mathrm{C}$ with constant stirring using $100 \mu \mathrm{l}$ of thiophilic resin (Pierce) previously equilibrated with TMG buffer. The clear extract was incubated overnight with
$50 \mu \mathrm{l}$ of purified anti-His-PfNMNAT IgY antibody from chicken serum at $4{ }^{\circ} \mathrm{C}$ with constant stirring. $100 \mu \mathrm{l}$ of thiophilic resin previously equilibrated with TMG buffer was added, and the sample was incubated for 2 rs at $4{ }^{\circ} \mathrm{C}$ with constant stirring. The immunoprecipitate was obtained by centrifuging the samples at $4500 \times g$ for $3 \mathrm{~min}$ at $4{ }^{\circ} \mathrm{C}$. The precipitate obtained was washed 3 times with $500 \mu \mathrm{l}$ of TMG buffer for $10 \mathrm{~min}$ in each case. The final pellet was resuspended in $80 \mu \mathrm{l}$ of loading buffer for SDSPAGE and incubated in boiling water for $6 \mathrm{~min}$. The samples obtained were analysed by silver-stained SDS-PAGE. At the same time, Western blotting was performed with anti-His-PfNMNAT antibodies and antibodies to identify phosphorylations at the $\mathrm{S}, \mathrm{Y}$ and $\mathrm{T}$ residues (Sigma).

\section{Results}

\section{Development of an immunological tool for PfNMNAT identification}

Avian and murine antibodies were evaluated by western blot using a recombinant protein (His-PfNMNAT). Both IgG and IgY at a dilution of 1:5000 recognize up to $15 \mathrm{ng}$ of the purified recombinant protein. Figure 1 shows the evaluation of IgG, where the electrophoretic separation of His-PfNMNAT $(\sim 28 \mathrm{kDa})$ and bovine serum albumin (BSA, $\sim 66 \mathrm{kDa}$ ), used as a non-specific control, can be observed (a). Antibodies specifically recognized the recombinant protein (c). Similar results were obtained with IgY (Additional files 1 and 2).

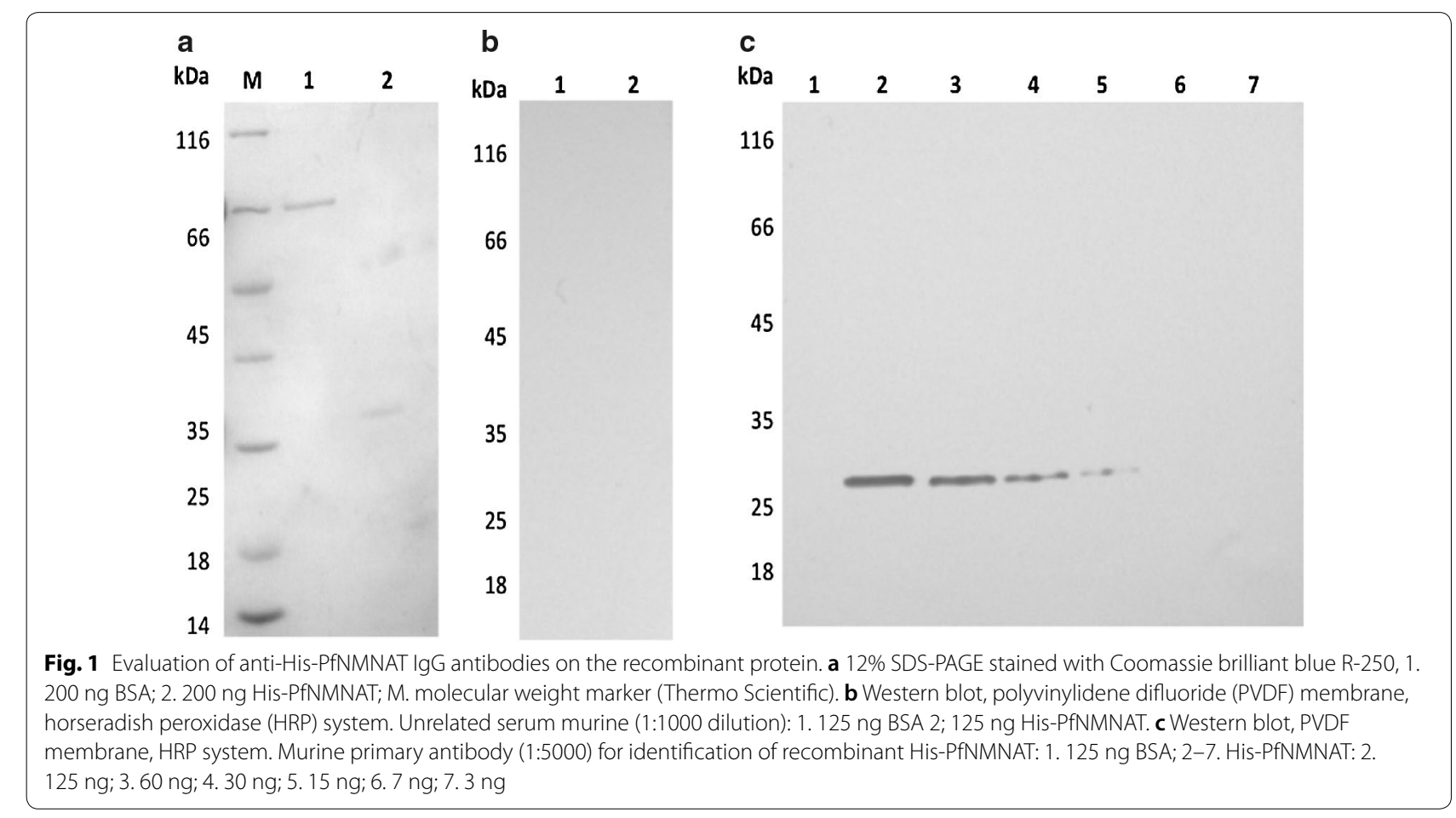




\section{a}

b

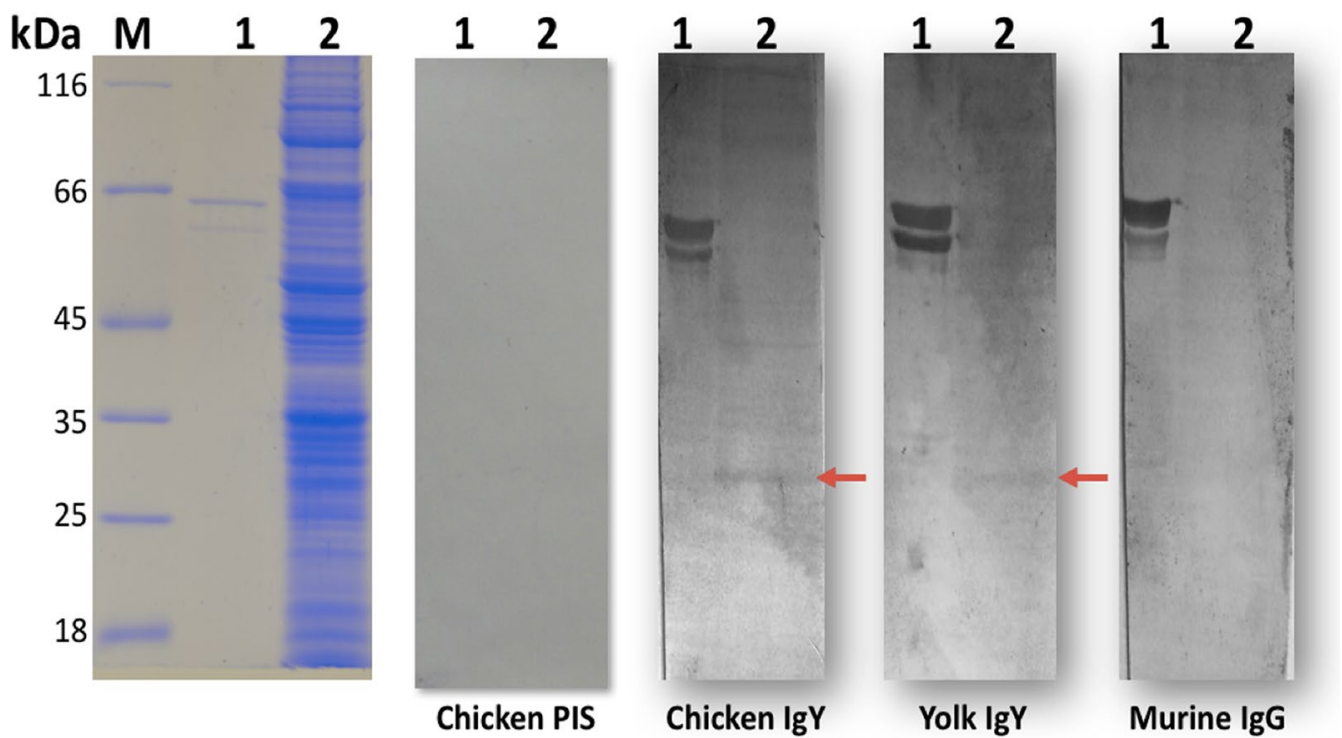

Fig. 2 Evaluation of anti-His-PfNMNAT IgY and IgG antibodies on Plasmodium falciparum asynchronous extracts. a 12\% SDS-PAGE stained with Coomassie brilliant Blue R-250. b PVDF membrane. 1. Positive control: Recombinant protein MBP-PfNMNAT (66 kDa). 2. 80 Mg of Plasmodium falciparum FCR3 extract from asynchronous culture. M. molecular weight marker (Thermo Scientific). The red arrow shows the identification of a protein of approximately $28 \mathrm{kDa}$ corresponding to endogenous PfNMNAT. Primary antibody 1:1000 (pre-imune serum IgY, anti-His-PfNMNAT chicken serum IgY, anti-His-PfNMNAT egg yolk IgY, or murine blood IgG), secondary antibody 1:8000 (biotinylated anti-lgY or anti-lgG), streptavidinalkaline phosphatase 1:8000, developed with the chromogenic 5-bromo-4-chloro-3'-indolyphosphate/nitro-blue tetrazolium (BCIP/NBT) substrate system

\section{PfNMNAT is identified in the soluble extracts of the parasite}

By employing the above-mentioned antibodies on cellular extracts from asynchronous cultures of $P$. falciparum, a band of $\sim 28 \mathrm{kDa}$ (slightly larger than the expected theoretical mass $\sim 26 \mathrm{kDa}$ ), was immunodetected, in addition to the identification of the control recombinant protein (MBP-PfNMNAT). When pre-immune serum was used, there was no identification, as expected (Fig. 2). The difference in mass possibly corresponds to a posttranslational protein modification, taking into account what has been reported for other NMNATs. HsNMNAT-1 contains one serine residue (Ser136), which is a phosphorylation target of protein kinase $C$ enzymes, and is involved in the regulation of the catalytic activity of the self-modified PARP1 enzyme [21]. It has recently been found that Trypanosoma cruzi NMNAT has one or more serine-phosphorylated residues [22], which are possibly necessary for its regulation. PfNMNAT may be regulated by phosphorylation in some of its residues.

\section{PfNMNAT is a phosphorylation target}

The NetPhos 3.1 server [23] predicted 21 possible phosphorylation sites for PfNMNAT: 15 for serine, 2 for tyrosine and 4 for threonine. To determine whether
PfNMNAT is a phosphorylation target at some of its residues, protein immunoprecipitation was performed in the soluble extract of the parasite using both murine and chicken serum antibodies. Immunoprecipitated proteins were subjected to Western blot analysis with antiphosphorylated $\mathrm{S}, \mathrm{Y}$ and $\mathrm{T}$ antibodies, as described in the methodology. In both experiments, the results were congruent, finding that PfNMNAT is phosphorylated at one or more serine, tyrosine and threonine residues (Fig. 3). Pease et al., by means of a phosphoproteome analysis of the parasite using mass spectrometry, found that the residue of serine 167 is a phosphorylation target and has a maximum peak of modification in the ring stage [24]. This corroborates the results obtained and could be an explanation for the increase in protein size displayed in the Western blot analysis.

\section{PfNMNAT is located in the cytoplasm of the parasite}

The anti-His-PfNMNAT IgY antibody identifies PfNMNAT with a cytoplasmic pattern. Pre-immune chicken serum was used as a negative control (Fig. 4). Identification was not homogeneous within the cytoplasm of the parasite since there were aggregation points, which can be due to concentration of the protein in specific points or organelles. 

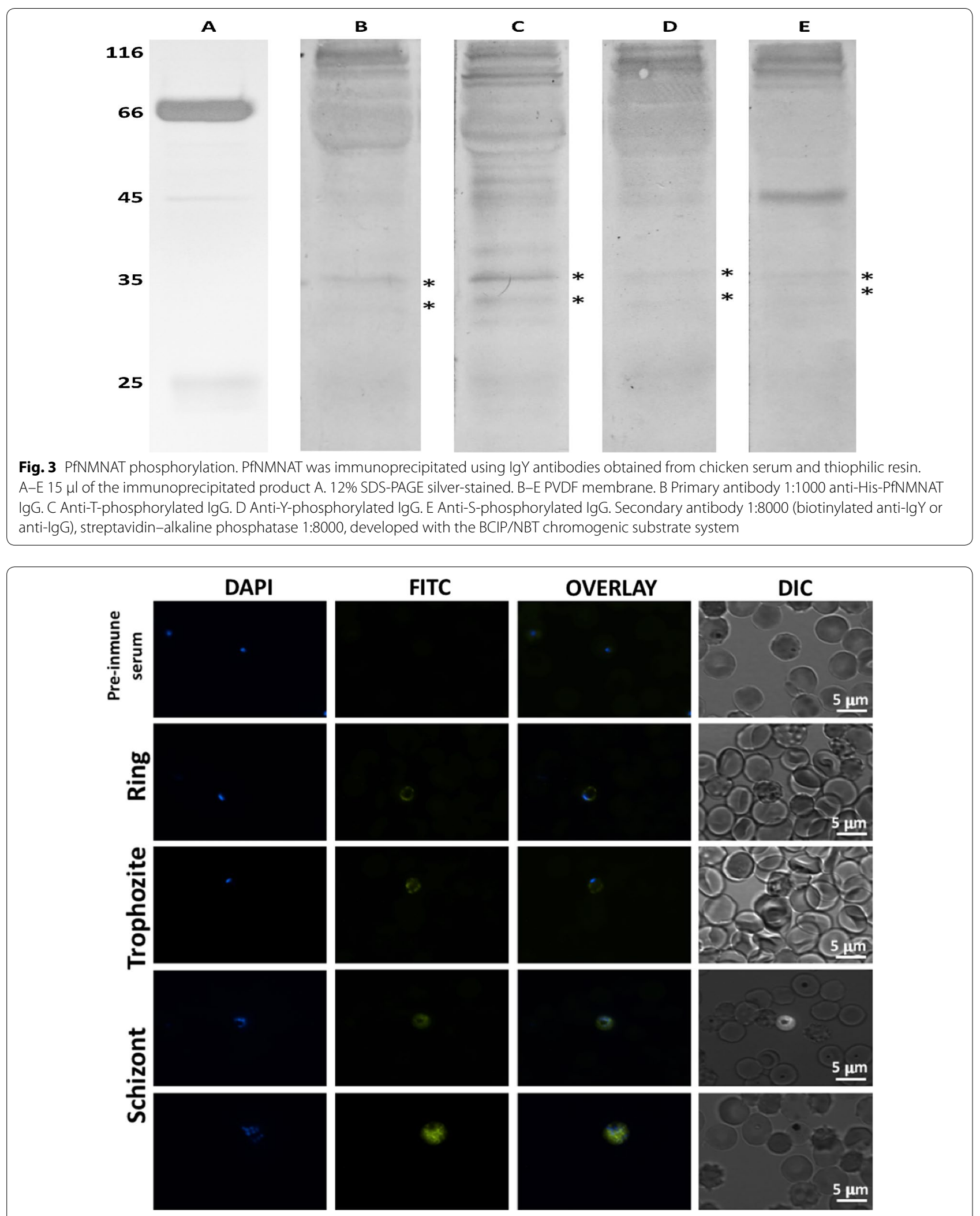

Fig. 4 Immunolocalization of PfNMNAT at different stages of the asexual life cycle of Plasmodium falciparum. Primary antibody: anti-His-PfNMNAT IgY serum (1:250). Unrelated serum (1:250). Secondary anti-a-FITC IgY antibodies (1:1000). Nuclear staining with 4',6-diamidino-2-phenylindole (DAPl, $1 \mu \mathrm{g} / \mathrm{ml})$. The images were taken at $\times 100$ magnification using a Nikon C1 plus confocal fluorescence microscope 
The use of anti-His-PfNMNAT IgY antibodies specifically showed the protein in the cytoplasm in all three stages of the asexual life cycle (Fig. 5). These results of the immunodetection and immunolocalization of the endogenous protein confirm the localization described by O'Hara et al. where the overexpression of the GFPcoupled recombinant protein in the carboxy-terminal region shows a cytoplasmic profile as well as a possible punctuated pattern of cytoplasmic accumulation [12]. The same localization has been reported for other NMNATs, e.g., mouse [25], yeast [26] and for one of the NMNAT isoforms of Drosophila melanogaster [27]. The $\mathrm{NAD}+$ synthesized in this compartment can be used in cytoplasmic processes, such as in mobilizing calcium to the endoplasmic reticulum as precursor molecules of agents, in metabolic pathways such as glycolysis [28], and in the synthesis of calcium-mobilizing agents such as cyclic adenosine diphosphate ribose (cADPR) and nicotinic acid adenine dinucleotide phosphate (NAADP) [29]. The fact that the parasite only has one NMNAT, could be attributed a simplified metabolic pathways in the parasite, as well as intracellular parasites such as Leishmania braziliensis and Trypanosoma cruzi in comparison with free-living organisms $[9,10]$. In this way, NAD+ can be transported to the nucleus and mitochondria [30,31] by a still unknown mechanism.

\section{PfNMNAT expression varies during the asexual life cycle}

Western blot analysis of protein extracts using antiHis-PfNMNAT IgY serum, allowed identification that the PfNMNAT protein is expressed mostly in the ring (Fig. 6), being a result consistent with what is reported in the database of Plasmodium [32] whereby ribosomal profile, it was found that in the ring stage the PfNMNAT is translationally more active in comparison with the other stages of the asexual life cycle [33].

The results suggest that the regulation of PfNMNAT expression may be occurring at the post-transcriptional level, as has been shown for the parasite in recent studies $[34,35]$, because the overall analysis of transcripts for
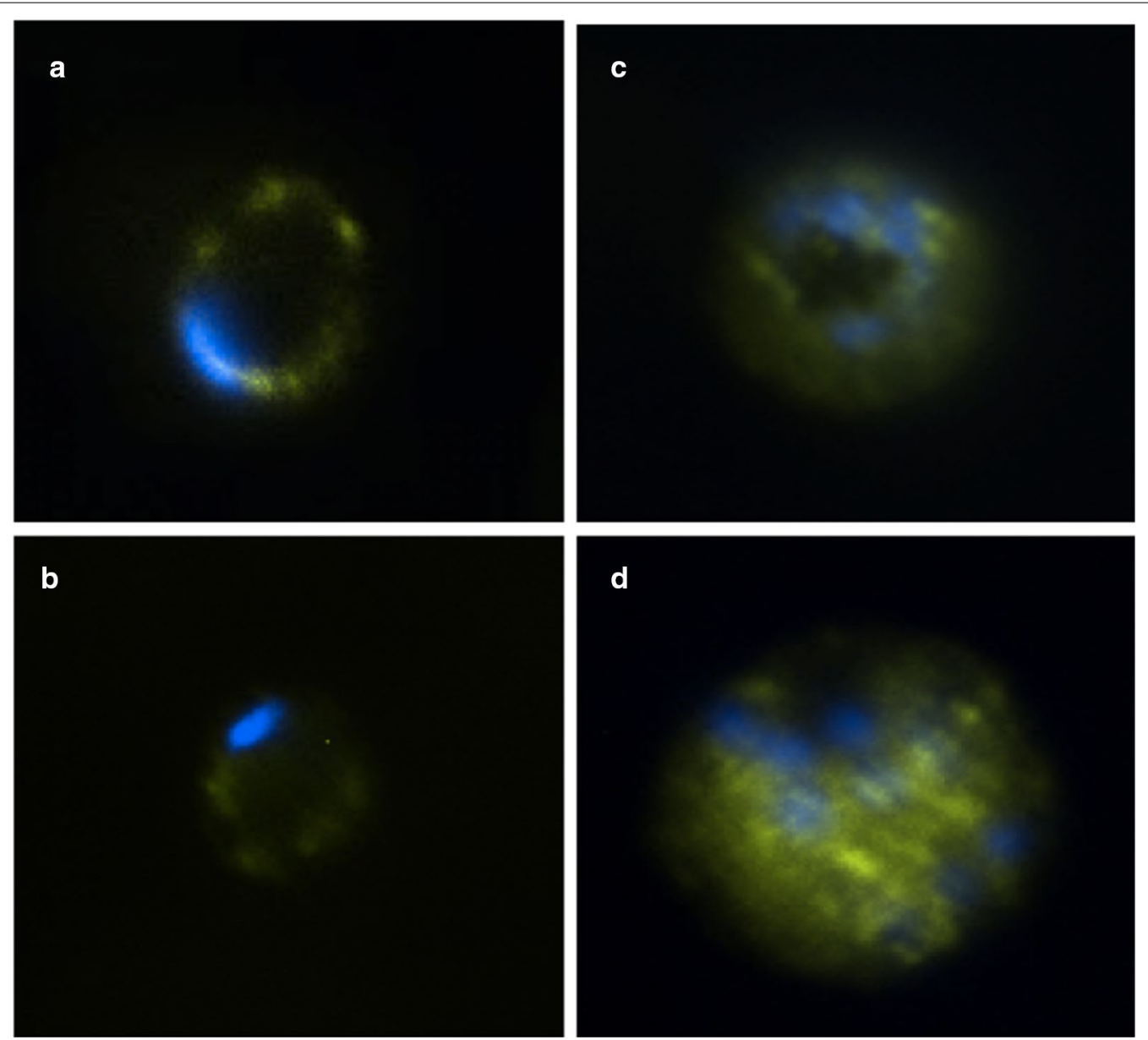

Fig. 5 Magnified image of PfNMNAT localization by fluorescence microscopy using IgY antibody. Recognition of the PfNMNAT protein in the FCR3 strain of $P$. falciparum in the stages of rings (a), trophozoite $(\mathbf{b})$ and schizonts (c, d). Primary anti-His-PfNMNAT IgY antibody (1:250); secondary anti-a-FITC IgY antibody (1:1000); nuclear staining with DAPI (1 $\mu \mathrm{g} / \mathrm{ml})$ 

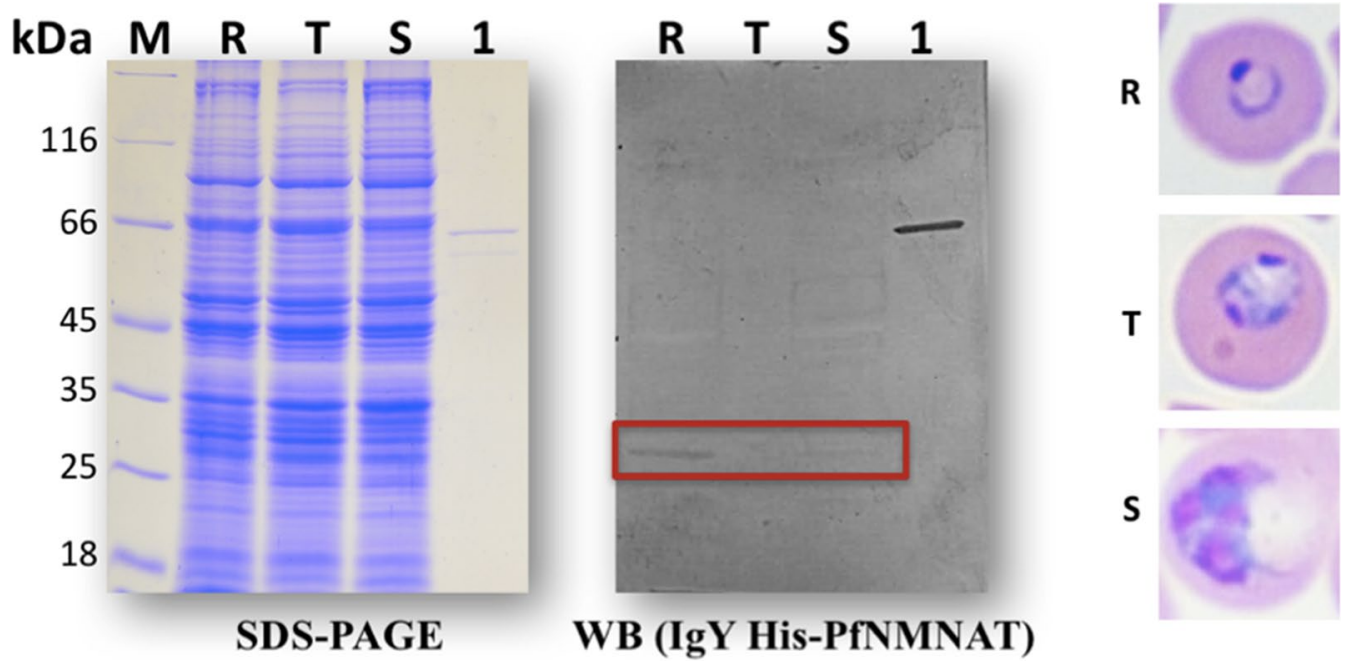

Fig. 6 Protein expression analysis of PfNMNAT. $150 \mu \mathrm{g}$ protein from the ring (R), trophozoite (T) and schizont (S) stages were loaded. As a positive control, $150 \mathrm{ng}$ of recombinant protein MBP-PfNMNAT (66 kDa) was loaded (1). M. molecular weight marker (Thermo Scientific). 12\% SDS-PAGE stained with Coomassie Blue R-250 and western blot on a PVDF membrane. Primary anti-His-PfNMNAT IgY antibody (1:1000). Secondary antibody: biotinylated anti-chicken (1:8000). Streptavidin-alkaline phosphatase (1:8000). Developed with the BCIP/NBT substrate system

Plasmodium revealed that NMNAT does not have significant variations in the asexual life cycle [36]. The parasite genome does not code for specialized transcription factors, whereas there are many genes coding for binding proteins and RNA regulation, indicating a possible regulation at levels subsequent to transcription [37-39].

\section{Conclusion}

PfNMNAT was immunodetected using different antibodies, observing a higher molecular weight band than expected, which could be attributed to post-translational modification. The cytoplasmic intracellular localization of the NMNAT protein in P. falciparum parasites was proven in the three stages of the asexual life cycle. PfNMNAT was observed at the transcriptional and protein levels. Protein levels showed variations during the asexual life cycle, with one major expression peak in the ring stage. The results of this work suggest that PfNMNAT is being regulated at post-transcription levels.

\section{Additional files}

Additional file 1. Evaluation of anti-His-PfNMNAT IgY (Serum) antibodies on the recombinant protein.

Additional file 2. Evaluation of anti-His-PfNMNAT IgY (Yolk) antibodies on the recombinant protein.

\section{Authors' contributions}

LS was in charge of obtaining and evaluating the antibodies under the supervision of GD and MR. DS performed the preliminary assays for localization of the protein under the supervision of MR. CN performed the final localization assays, protein levels in the stages and phosphorylation assays under the supervision of MR. All authors read and approved the final manuscript

\section{Author details}

${ }^{1}$ Laboratorio de Investigaciones Básicas en Bioquímica (LIBBIQ), Facultad de Ciencias, Universidad Nacional de Colombia, Sede Bogotá, Bogotá D.C., Colombia. ${ }^{2}$ Laboratorio de Toxicología, Facultad de Medicina Veterinaria y Zootecnia, Universidad Nacional de Colombia, Sede Bogotá, Bogotá D.C., Colombia.

\section{Acknowledgements}

The authors thank COLCIENCIAS for funding Project 110156935240, the National University of Colombia, and the Faculty of Sciences. The authors thank the Laboratory of Molecular Parasitology at El Bosque University for their training in laboratory culture techniques.

\section{Competing interests}

The authors declare that they have no competing interests.

\section{Availability of data and materials}

Not applicable.

\section{Consent for publication \\ Not applicable.}

\section{Ethics approval and consent to participate}

The creation of antibodies has the ethical endorsement of the Facultad de Ciencias of the National University of Colombia, Sede Bogota.

\section{Funding}

This project was financed by Colciencias under the project 110156935240 and the National University of Colombia.

\section{Publisher's Note}

Springer Nature remains neutral with regard to jurisdictional claims in published maps and institutional affiliations.

Received: 6 June 2017 Accepted: 4 April 2018

Published online: 11 April 2018 


\section{References}

1. WHO. World malaria report. Geneva: World Health Organization; 2016.

2. WHO. Estrategia Técnica Mundial Contra La Malaria 2016-2030. Organización Mundial de la Salud; 2015.

3. Müller S. Redox and antioxidant systems of the malaria parasite Plasmodium falciparum. Mol Microbiol. 2004;53:1291-305.

4. Eren D. Plasmodium falciparum enzymes involved in redox balancing of nicotinimide nucleotides. Ph.D. dissertation, Drexel University College of Medicine, USA; 2003. p. 186.

5. Zerez CR, Roth EF, Schulman S, Tanaka KR. Increased nicotinamide adenine dinucleotide content and synthesis in Plasmodium falciparuminfected human erythrocytes. Blood. 1990;75:1705-10.

6. Lau C. The NMN/NaMN adenylyltransferase (NMNAT) protein family. Front Biosci. 2009;14:410-31.

7. Schweiger M, Hennig K, Lerner F, Niere M, Hirsch-Kauffmann M, Specht $T$, et al. Characterization of recombinant human nicotinamide mononucleotide adenylyl transferase (NMNAT), a nuclear enzyme essential for NAD synthesis. FEBS Lett. 2001;492:95-100.

8. Stancek M, Schnell R, Rydén-Aulin M. Analysis of Escherichia coli nicotinate mononucleotide adenylyltransferase mutants in vivo and in vitro. BMC Biochem. 2005;6:16.

9. Berger F, Lau C, Dahlmann M, Ziegler M. Subcellular compartmentation and differential catalytic properties of the three human nicotinamide mononucleotide adenylyltransferase isoforms. J Biol Chem. 2005;280:36334-41.

10. Lau C, Dölle C, Gossmann TI, Agledal L, Niere M, Ziegler M. Isoformspecific targeting and interaction domains in human nicotinamide mononucleotide adenylyltransferases. J Biol Chem. 2010;285:18868-76.

11. Marín C. Identificación, expresión y caracterización de la nicotinamida/ nicotinato mononucleótido adenililtransferasa de Plasmodium falciparum (PfNMNAT). Bogota: Universidad Nacional de Colombia; 2010. p. 117.

12. O'Hara JK, Kerwin LJ, Cobbold SA, Tai J, Bedell TA, Reider PJ, et al. Targeting $\mathrm{NAD}+$ metabolism in the human malaria parasite Plasmodium falciparum. PLOS ONE. 2014;9:e94061.

13. Bathke J, Fritz-Wolf K, Brandstädter C, Burkhardt A, Jortzik E, Rahlfs S, et al. Structural and functional characterization of Plasmodium falciparum nicotinic acid mononucleotide adenylyltransferase. J Mol Biol. 2016:428:4946-61.

14. Harlow E, Lane D. Antibodies: a laboratory manual. Cold Spring: Cold Spring Harbor Laboratory Press; 1988. p. 726.

15. Fang $L$. Antibody purification from Western blotting. Bio protocol. 2012;2:e133.

16. Lomonte B. (2007) Manual de Métodos Inmunológicos. Universidad de Costa Rica, 138 pp. http://www.icp.ucr.ac.cr/ blomonte/. Accessed 28 Mar 2018.

17. Trager W, Jensen JB. Human malaria parasites in continuous culture. Science. 1976;193:673-5.

18. Lambros C, Vanderberg JP. Synchronization of Plasmodium falciparum stages in culture. J Parasitol. 1979;65:418-20.

19. Nieto CA, Forero N, Ramírez MH. Design and production of various fusion proteins of the nicotinamide/nicotinate mononucleotide adenili transferase (NMNAT) of Plasmodium falciparum. Rev Colomb Química. 2017:46:5-10.

20. Tonkin CJ, Van Dooren GG, Spurck TP, Struck NS, Good RT, Handman E, et al. Localization of organellar proteins in Plasmodium falciparum using a novel set of transfection vectors and a new immunofluorescence fixation method. Mol Biochem Parasitol. 2004;137:13-21.

21. Berger F, Lau C, Ziegler M. Regulation of poly(ADP-ribose) polymerase 1 activity by the phosphorylation state of the nuclear NAD biosynthetic enzyme NMN adenylyl transferase 1. Proc Natl Acad Sci USA. 2007;104:3765-70.

22. Sánchez-Lancheros DM, Ospina-Giraldo LF, Ramírez-Hernández MH Nicotinamide mononucleotide adenylyltransferase of Trypanosoma cruzi (TCNMNAT): a cytosol protein target for serine kinases. Mem Inst Oswaldo Cruz. 2016;111:670-5.
23. Blom N, Gammeltoft S, Brunak S. Sequence and structure-based prediction of eukaryotic protein phosphorylation sites. J Mol Biol. 1999:294:1351-62.

24. Pease BN, Huttlin EL, Jedrychowski MP, Talevich E, Harmon J, Dillman T, et al. Global analysis of protein expression and phosphorylation of three stages of Plasmodium falciparum intraerythrocytic development. J Proteome Res. 2013:12:4028-45.

25. Sasaki Y, Araki T, Milbrandt J. Stimulation of nicotinamide adenine dinucleotide biosynthetic pathways delays axonal degeneration after axotomy. J Neurosci. 2006;26:8484-91.

26. Kato M, Lin SJ. YCL047C/POF1 is a novel nicotinamide mononucleotide adenylyltransferase (NMNAT) in Saccharomyces cerevisiae. J Biol Chem. 2014;289:15577-87.

27. Zhai RG, Cao Y, Hiesinger PR, Zhou Y, Mehta SQ, Schulze KL, et al. Drosophila NMNAT maintains neural integrity independent of its NAD synthesis activity. PLoS Biol. 2006;4:2336-48.

28. Roth F, Raventos-suarez C, Nagel RL, Annenberg P. Glutathione stability and oxidative stress in $P$. falciparum infection in vitro: responses of normal and G6PD deficient cells. Biochem Biophys Res Commun. 1982;109:355-62.

29. Berger F, Ramírez-Hernández MH, Ziegler M. The new life of a centenarian: signalling functions of NAD(P). Trends Biochem Sci. 2004;29:111-8.

30. Palmieri F, Rieder B, Ventrella A, Blanco E, Do PT, Nunes-Nesi A, et al. Molecular identification and functional characterization of Arabidopsis thaliana mitochondrial and chloroplastic NAD+ carrier proteins. J Biol Chem. 2009;284:31249-59.

31. Todisco S, Agrimi G, Castegna A, Palmieri F. Identification of the mitochondrial NAD+ transporter in Saccharomyces cerevisiae. J Biol Chem. 2006;281:1524-31.

32. PlasmoDB. http://plasmodb.org/plasmo/app/record/gene/PF3D7_13276 00. Accessed 28 Mar 2018

33. Caro F, Ahyong V, Betegon M, DeRisi JL. Genome-wide regulatory dynamics of translation in the Plasmodium falciparum asexual blood stages. Elife. 2014;3:e04106.

34. Doerig C, Rayner JC, Scherf A, Tobin AB. Post-translational protein modifications in malaria parasites. Nat Rev Microbiol. 2015:13:160-72.

35. Cui L, Lindner S, Miao J. Translational regulation during stage transitions in malaria parasites. Ann NY Acad Sci. 2015;1342:1-9.

36. López-Barragán MJ, Lemieux J, Quiñones M, Williamson KC, Molina-Cruz A, Cui K, et al. Directional gene expression and antisense transcripts in sexual and asexual stages of Plasmodium falciparum. BMC Genomics. 2011;12:587.

37. Coulson R, Hall N, Ouzounis C. Comparative genomics of transcriptional control in the human malaria parasite Plasmodium falciparum. Genome Res. 2004;14:1548-54

38. Gardner MJ, Hall N, Fung E, White O, Berriman M, Hyman RW, et al. Genome sequence of the human malaria parasite Plasmodium falciparum. Nature. 2002;419:498-511.

39. Reddy BPN, Shrestha S, Hart KJ, Liang X, Kemirembe K, Cui L, et al. A bioinformatic survey of RNA-binding proteins in Plasmodium. BMC Genomics. 2015;16:890.

Ready to submit your research? Choose BMC and benefit from

- fast, convenient online submission

- thorough peer review by experienced researchers in your field

- rapid publication on acceptance

- support for research data, including large and complex data types

- gold Open Access which fosters wider collaboration and increased citations

- maximum visibility for your research: over 100M website views per year

At BMC, research is always in progress.

Learn more biomedcentral.com/submissions 